\title{
A Lidar and Backscatter Sonde Measurement Campaign at Table Mountain during February-March 1997: Observations of Cirrus Clouds
}

\author{
G. Beyerle,*,**,\#\# M. R. Gross, ${ }^{+}$D. A. Haner, ${ }^{\#}$ N. T. Kuome, $@$ I. S. McDermid,* T. J. McGee, \& \\ J. M. Rosen, @ H.-J. SCHÄFER,**,++ AND O. SCHREMS** \\ * Jet Propulsion Laboratory, California Institute of Technology, Wrightwood, California \\ $+{ }_{+}$Joint Center for Earth Systems Technology, University of Maryland, Baltimore County, Baltimore, Maryland \\ \# Department of Chemistry, California State Polytechnic University, Pomona, California \\ @ Department of Physics and Astronomy, University of Wyoming, Laramie, Wyoming \\ \& Goddard Space Flight Center, Greenbelt, Maryland \\ ** Alfred Wegener Institute for Polar and Marine Research, Bremerhaven and Potsdam, Germany
}

(Manuscript received 19 May 1999, in final form 1 September 2000)

\section{ABSTRACT}

\begin{abstract}
Results from a measurement campaign performed at Table Mountain Facility/Jet Propulsion Laboratory/ California Institute of Technology $\left(34.38^{\circ} \mathrm{N}, 117.68^{\circ} \mathrm{W}, 2280 \mathrm{~m} \mathrm{ASL}\right)$ are presented. Between 19 February and 18 March 1997 more than $400 \mathrm{~h}$ worth of lidar data were acquired and four backscatter sondes were launched. About $50 \%$ of the observations show the presence of cirrus clouds at altitudes close to and below the tropopause. Of these clouds $80 \%$ are characterized as subvisual with optical depths below 0.03 at a wavelength of $532 \mathrm{~nm}$. Simple geometrical considerations lead to cloud spatial scales of $0.31 \mathrm{~km}$ vertically and $7.5 \mathrm{~km}$ horizontally, respectively. Deviations from color ratio values derived on the basis of geometrical optics are interpreted as small particle signatures. Comparing backscatter ratio profiles observed concurrently by three aerosol lidars, mean deviations of about $10 \%$ are found.
\end{abstract}

\section{Introduction}

For many years frequent occurrences of cirrus clouds at tropical and midlatitudes have been observed by satellite remote sensors (Prabhakara et al. 1988; Wang et al. 1994). Because of their global distribution these cloud layers influence the radiation budget of the atmosphere (e.g., Stephens et al. 1990; Liou 1986). Recently, high-altitude cirrus have been studied with respect to heterogeneous processing potential of cirrus ice particles leading to chlorine activation (Borrmann et al. 1996; Reichardt et al. 1996; Solomon et al. 1997).

We present results from the aerosol and cloud measurement campaign STRAIT'97 carried out at Table Mountain in southern California $\left[34.38^{\circ} \mathrm{N}, 117.68^{\circ} \mathrm{W}\right.$, $2280 \mathrm{~m}$ above sea level (ASL)] during February-March 1997. Three ground-based aerosol lidar instruments (two with polarization capability) participated in the

\footnotetext{
\#\# Current affiliation: GeoForschungsZentrum, Potsdam, Germany.

++ Current affiliation: INNOSOFT GmbH, Cologne, Germany.
}

Corresponding author address: Dr. Georg Beyerle, GeoForschungsZentrum (GFZ), Telegrafenberg A17/PB1.1, Division Kinematics and Dynamics of the Earth, D-14473 Potsdam, Germany. E-mail: gbeyerle@gfz-potsdam.de campaign; four balloon-borne backscatter sondes were launched to provide in situ data on cloud and aerosol optical parameters. The objective of the campaign and purpose of this study is twofold. First, the measurements enhance the dataset on occurrence frequencies of visible and subvisible cirrus clouds at midlatitude. Second, ground-based lidar observations of the tropo- and stratosphere are an integral part of the Network for the Detection of Stratospheric Change (NDSC) where they provide information on trace gas concentrations, temperature, aerosol content, and cloud occurrences. The high-quality level of the NDSC dataset is guaranteed by periodic intercomparisons between instruments (e.g., McDermid et al. 1995; Singh et al. 1996; Steinbrecht et al. 1998). Results from the individual instruments were compared in order to improve our understanding of systematic and statistical error sources in the lidar dataset.

The paper is organized as follows. First, the measuring instruments are briefly characterized, second, measurement results and data analysis procedures are described, and, finally, the cirrus cloud observations are analyzed and discussed.

\section{Instruments}

Three aerosol lidar instruments participated in the STRAIT'97 measurement campaign. The mobile aero- 
TABLE 1. Technical details of the three lidar instruments participating in STRAIT'97.

\begin{tabular}{llll}
\hline \hline & \multicolumn{1}{c}{ AT-lidar } & \multicolumn{1}{c}{ TAL } & MARL \\
\hline Laser type: & XeF, Nd:YAG & Nd:YAG & Nd:YAG \\
Rep. rate: & $50 \mathrm{~Hz}$ at $532 \mathrm{mn}$ & $10 \mathrm{~Hz}$ & $30 \mathrm{~Hz}$ \\
& $200 \mathrm{~Hz}$ at $351 \mathrm{~nm}$ & & $280 \mathrm{~mJ}$ at $532 \mathrm{~nm}$ \\
Pulse energy: & $300 \mathrm{~mJ}$ at $532 \mathrm{~nm}$ & $400 \mathrm{~mJ}$ at $532 \mathrm{~nm}$ & $360 \mathrm{~mJ}$ at $355 \mathrm{~nm}$ \\
& $100 \mathrm{~mJ}$ at $351 \mathrm{~nm}$ & $300 \mathrm{~mJ}$ at $355 \mathrm{~nm}$ & $532 \mathrm{and} 355 \mathrm{~nm}$ \\
Transm. wvl.: & 532 and $351 \mathrm{~nm}$ & 1064,532, and $355 \mathrm{~nm}$ & $607,532,387,355 \mathrm{~nm}$ \\
Detected wvl.: & $532,382,351 \mathrm{~nm}$ & $1064,532,387,355 \mathrm{~nm}$ & $5 \mathrm{~nm}$ at $355 \mathrm{~nm}$ \\
Filter FWHM: & & $2 \mathrm{~nm}$ at $355 \mathrm{~nm}$ & $10 \mathrm{~nm}$ at $532 \mathrm{~nm}$ \\
& & $1 \mathrm{~nm}$ at $532 \mathrm{~nm}$ & $10 \times$ \\
Beam exp.: & $5 \times(532 \mathrm{~nm})$ & & $1.14 \mathrm{~m}$ \\
& $1 \times(351 \mathrm{~nm})$ & $0.44 \mathrm{~m}$ & $f / 3.1$ \\
Telescope diam.: & $0.91 \mathrm{~m}$ & $f / 3.8$ & $0.2 \mathrm{mrad}$ \\
$f$-number: & $f / 2.5$ & $>10 \mathrm{mrad}$ & Photon counting \\
Field of view: & $1.9 \mathrm{mrad}$ & Photon counting & Analog mode \\
Detection mode: & Photon counting & $2 \mu \mathrm{s}$ & $800 \mathrm{nsec}$ (typ.) \\
& & $300 \mathrm{~m}$ & $120 \mathrm{~m}$ (typ.) \\
Dwell time: & 1 or $2 \mu \mathrm{s}$ & & \\
Altitude res.: & 150 or $300 \mathrm{~m}$ & &
\end{tabular}

sol temperature lidar (AT-lidar) from NASA Goddard Space Flight Center; the Mobile Aerosol Raman Lidar (MARL) from Alfred Wegener Institute, Germany; and the Table Mountain Aerosol Lidar (TAL) from Jet Propulsion Laboratory/Table Mountain Facility. In addition, four balloon-borne backscatter sondes from University of Wyoming were launched during the campaign.

\section{a. Lidar instruments}

The AT-lidar and MARL are mobile systems accommodated in a $40-\mathrm{ft}$ trailer and $20-\mathrm{ft}$ container, respectively. TAL is an in-house instrument located at Table Mountain Facility (TMF).

In all three lidar instruments a $\mathrm{Nd}: \mathrm{YAG}$ laser serves as light source. The second (532 nm) and third (355 $\mathrm{nm}$ ) harmonic of the $1064 \mathrm{~nm}$ fundamental wavelength are transmitted simultaneously with pulse repetition frequencies of 10 and $30 \mathrm{~Hz}$ in the case of TAL and MARL, respectively. AT-lidar transmits the Nd:YAG second harmonic at $50 \mathrm{~Hz}$ and a $\mathrm{XeF}$ excimer laser generates output at $351 \mathrm{~nm}$.

Both elastically backscattered light from molecular and particulate scattering and that from inelastic vibra-

TABLE 2. Technical details of the backscatter sonde.

\begin{tabular}{ll}
\hline \hline Light source: & Xe flash lamp \\
Emitted light energy: & $7 \mathrm{~J}$ per pulse \\
Detected wavelengths: & 940 and $490 \mathrm{~nm}$ \\
Filter width: & about $150 \mathrm{~nm}$ \\
Pulse repetition frequency: & about $1 / 7 \mathrm{~Hz}$ \\
Height resolution: & $25-35 \mathrm{~m}$ \\
Detectors: & Photodiodes \\
SNR: & About 100 at $20 \mathrm{~km}$ \\
Additional sensors: & Temperature, pressure, ozone \\
& partial pressure, rel. humidity \\
Weight: & $7 \mathrm{~kg}$ \\
Balloon volume: & $1500 \mathrm{~m}^{3}$ \\
\hline
\end{tabular}

tional Raman scattering by molecular nitrogen are detected for altitude ranges between the midtroposphere and $30 \mathrm{~km}$, typically. In addition, TAL and MARL include detection channels for cross-polarized return signals at $532 \mathrm{~nm}$ (TAL and MARL) and $355 \mathrm{~nm}$ (MARL only). All lidar instruments were prepared for nighttime operation.

Key instrument parameters of the three lidars are summarized in Table 1. For further information on technical details of MARL refer to Schäfer et al. (1995, 1997).

\section{b. Backscatter sonde}

The backscatter sonde is a balloon-borne instrument for the in situ observation of stratospheric aerosols (Rosen and Kjome 1991). The instrument measures the light backscattered at a distribution of angles peaking at $173^{\circ}$ at two wavelength ranges centered at 490 and $940 \mathrm{~nm}$, respectively. The transmitted light signal is a $7 \mathrm{~J}$ light pulse produced by a xenon flashlamp every $7-8 \mathrm{~s}$. The technical details are summarized in Table 2. The sonde observes an air volume of about $1 \mathrm{~m}^{3}$ within a few meters distance. At an average rise velocity of about $4-5 \mathrm{~m} \mathrm{~s}^{-1}$ the altitude resolution is $25-35 \mathrm{~m}$.

The backscattered light is measured by two photodiode detectors. Glass filters with a full width at half maximum (FWHM) of approximately $150 \mathrm{~nm}$ centered at wavelengths of 490 and $940 \mathrm{~nm}$, respectively, allow the determination of backscatter ratio at these two wavelengths. The pulse-to-pulse variation of the flashlamp (about $1.5 \%$ pulse-to-pulse, about $10 \%$ during one sounding) is monitored to make corrections to each channel. At $20 \mathrm{~km}$ altitude signal-to-noise ratio is about 100. The sonde includes additional sensors for measurement of ambient air temperature, air pressure, ozone partial pressure, and relative humidity. For further technical details refer to Rosen and Kjome (1991). 
TABLE 3. Listing of lidar measurements and backscatter sonde soundings. Times and dates are given in UTC. (Local time at TMF is Pacific standard time $=$ UTC -8 h.) Sunset times changed from 0302 to 0324 UTC between 19 Feb and 18 Mar. Occurrences of cirrus layers are marked in the last column. (note $2 / 19 / 97=19$ Feb 1997.)

\begin{tabular}{|c|c|c|c|c|c|}
\hline Date & AT-lidar & MARL & TAL & BKS & Cirrus \\
\hline 2/19/97 & & $1011-1401$ & $0746-1127$ & & $\times$ \\
\hline $2 / 20 / 97$ & & $0513-1253$ & 0309-0848 & & $\times$ \\
\hline $2 / 21 / 97$ & & 0554-1406 & 0544-1301 & & $\times$ \\
\hline $2 / 22 / 97$ & & $0237-1338$ & $0522-1342$ & & $\times$ \\
\hline $2 / 23 / 97$ & & 0459-1355 & 0243-1219 & & \\
\hline $2 / 24 / 97$ & & $0245-1406$ & $0351-1112$ & & \\
\hline $2 / 25 / 97$ & & $0637-1231$ & $0623-0925$ & & \\
\hline $2 / 27 / 97$ & & 0416-0754 & $0350-0801$ & & $x$ \\
\hline $3 / 1 / 97$ & & $0228-1253$ & 0326-0934 & & \\
\hline $3 / 2 / 97$ & 0508-0805 & $0245-1250$ & $0356-1013$ & & $\times$ \\
\hline $3 / 3 / 97$ & 0255-0601 & $0427-1326$ & $0605-1218$ & & $\times$ \\
\hline 3/4/97 & 0401-0825 & $0440-1417$ & $0400-1027$ & & $\times$ \\
\hline $3 / 5 / 97$ & $0325-0659$ & $0320-1342$ & 0646-1259 & & $\times$ \\
\hline 3/6/97 & 0447-0825 & 0441-1329 & $0435-1048$ & & \\
\hline $3 / 7 / 97$ & 0430-0955 & 0418-1346 & $0708-1144$ & & \\
\hline 3/8/97 & 0430-0631 & $0314-1345$ & 0907-1210 & & \\
\hline 3/9/97 & $0540-0755$ & $0458-1238$ & $0335-1216$ & & \\
\hline $3 / 10 / 97$ & 0415-0738 & 0442-1259 & $0317-1254$ & & \\
\hline $3 / 11 / 97$ & 0435-1106 & $0305-1355$ & $0550-1306$ & 0854-1020 & $\times$ \\
\hline $3 / 12 / 97$ & $0405-0755$ & 0357-1344 & $0313-1035$ & & $\times$ \\
\hline $3 / 13 / 97$ & 0402-0824 & $0256-1405$ & $0523-1135$ & 0606-0731 & $\times$ \\
\hline $3 / 14 / 97$ & & $0318-1358$ & & & $\times$ \\
\hline $3 / 15 / 97$ & & $0331-1403$ & $0542-1016$ & 0710-0842 & $\times$ \\
\hline $3 / 16 / 97$ & & 0411-0713 & 0548-0944 & & $\times$ \\
\hline $3 / 18 / 97$ & & & 0511-1008 & $0601-0731$ & \\
\hline Total & $44.5 \mathrm{~h}$ & $217.7 \mathrm{~h}$ & $151.4 \mathrm{~h}$ & & \\
\hline
\end{tabular}

\section{Measurements and data analysis}

The lidar and backscatter sonde measurements took place between 19 February and 18 March 1997 at TMF. During this time period four backscatter sondes were launched and lidar measurements were performed on 25 nights exclusively. Total measurement time of all three lidars was $413.6 \mathrm{~h}$. An overview of individual measurement periods is given in Table 3. Note that times are given in UTC, local time at TMF is Pacific standard time (PST $=$ UTC $-8 \mathrm{~h})$. Typically, lidar measurements started simultaneously after sunset and continued for 3-10 h. The three lidars were placed in close proximity with MARL and TAL separated by about $30 \mathrm{~m}$. ATlidar was located about $300 \mathrm{~m}$ farther away. The laser beams of all three instruments pointed vertically upward. MARL's beam tilt angle with respect to TAL were measured to be $10 \mathrm{mrad} \pm 5 \mathrm{mrad}$.

\section{a. Lidar data analysis}

Since all three lidars use the second harmonic Nd: YAG wavelength at $532 \mathrm{~nm}$ there was concern about possible interference effects. However, inspection of the raw data profiles revealed no signatures of cross-talk between the instruments. As the pulsed lasers were not synchronized with each other any geometrical overlap between the telescope's field of views would have produced distinct cross-talk signatures taking into account the signals' dynamical range of about 4-5 orders of magnitude.
On 15 of the total of 25 measurement nights during the campaign, enhanced values of particulate backscatter coefficients indicated the presence of cirrus layers as shown in Table 3. An overview of cirrus clouds observations by TAL is presented in Figs. 1-3. The figures show the temporal evolution of backscatter ratio

$$
R(z)=\frac{\beta^{M}(z)+\beta^{P}(z)}{\beta^{M}(z)}
$$

at a wavelength of $532 \mathrm{~nm}$ and altitudes $z$ between 8 and $14 \mathrm{~km}$ on 12 nights between 20 February and 13 March 1997. Here, $\beta^{P}(z)$ and $\beta^{M}(z)$ denote the particulate and molecular backscatter coefficient at altitude $z$, respectively. For the graphical representation in Figs. 1-3 the profiles have been interpolated in time using Gaussian weights with a standard deviation of $1.4 \mathrm{~min}$; no smoothing is performed in the vertical direction. Tropopause altitude-marked by dashed lines-were derived from rawinsondes launched at Vandenberg, California (VBG; $\left.34.65^{\circ} \mathrm{N}, 120.57^{\circ} \mathrm{W}\right)$.

Particulate backscatter coefficients were derived from TAL data using Klett's algorithm [Ansmann et al. 1992; Klett 1985, Eq. (22)]. At the upper reference altitude range $\left[z_{t}-\Delta z_{t} / 2, z_{t}+\Delta z_{t} / 2\right]$ the atmosphere is assumed to be aerosol- and particle-free $(R=1)$ with $z_{t}=14.5$ $\mathrm{km}$ and $\Delta z_{t}=3 \mathrm{~km}$. Since the ratio of $\beta^{P}$ and particulate extinction coefficient $\sigma^{P}$, the backscatter-to-extinction ratio,

$$
\mathcal{K}=\frac{\beta^{P}}{\sigma^{P}}
$$




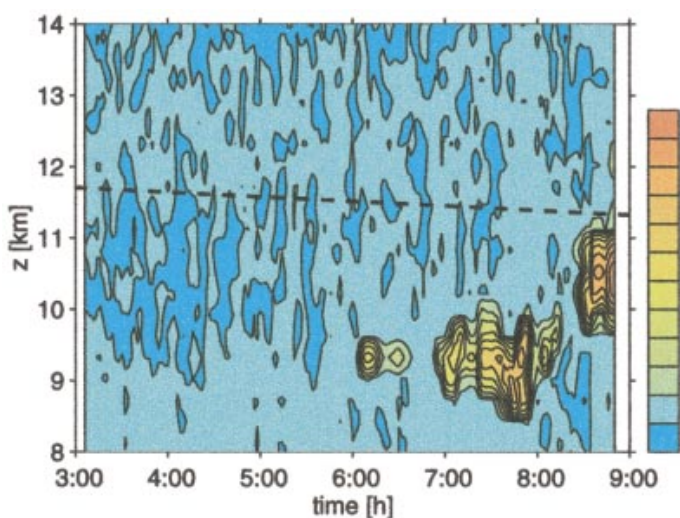

(a)
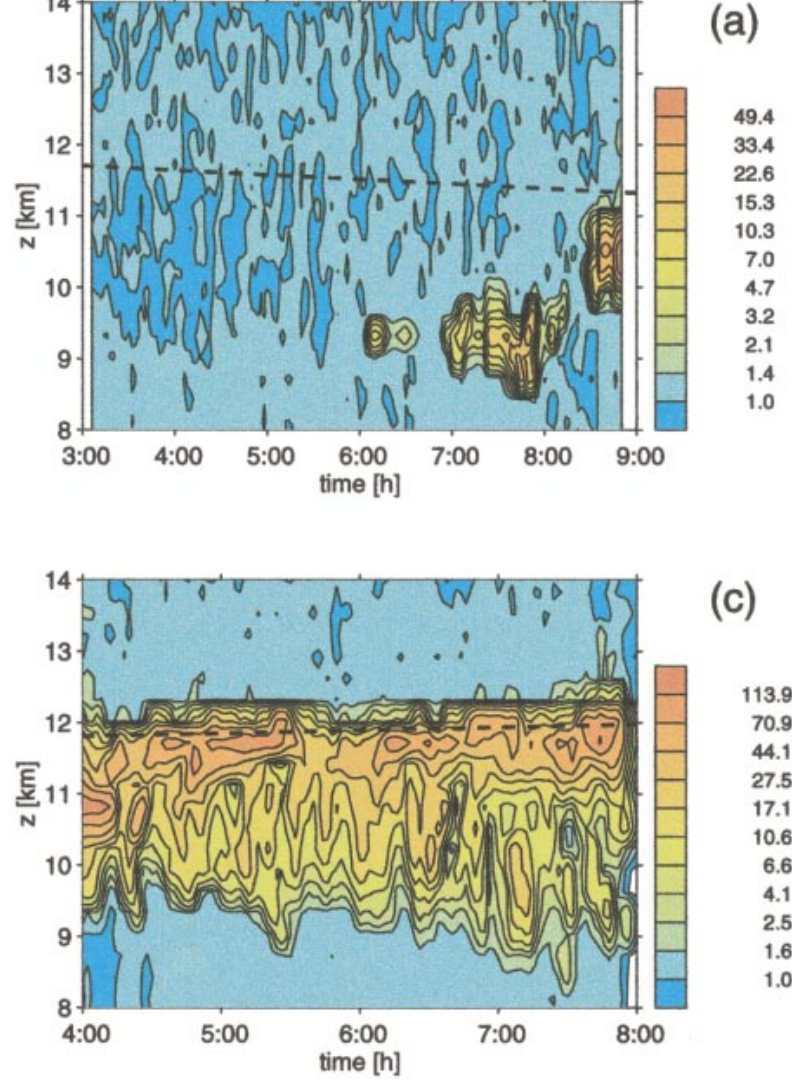

(c)

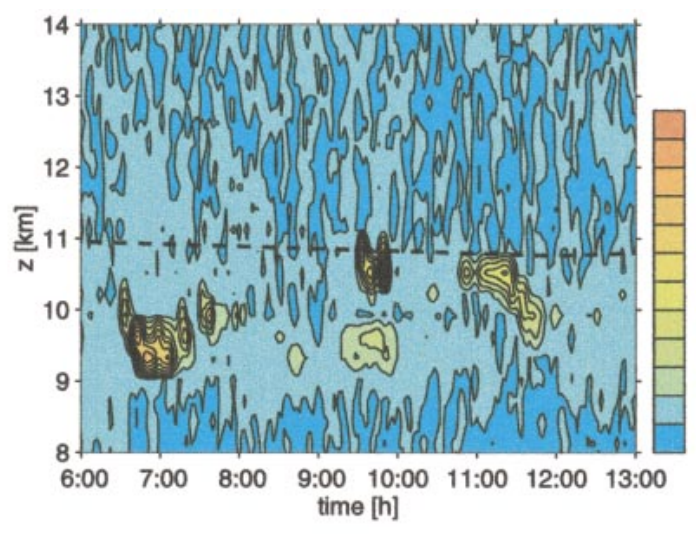

(b)

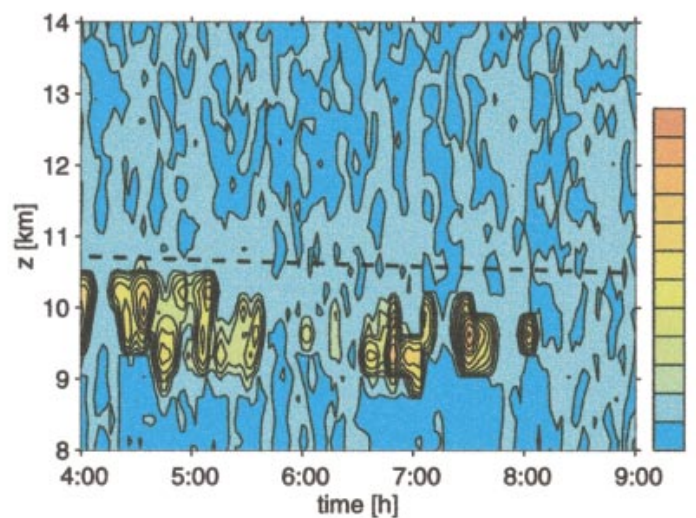

(d)

FIg. 1. Overview of cirrus cloud observations obtained on (a) $20 \mathrm{Feb}$, (b) $22 \mathrm{Feb}$, (c) $27 \mathrm{Feb}$, and (d) 2 Mar 1997. The plots shows the temporal evolution of backscatter ratio at $532 \mathrm{~nm}$ as a function of altitude. The dashed line marks the tropopause altitude as derived from rawinsonde launches at VBG. Times are given in UTC.

is known to vary significantly within cirrus clouds (e.g., Ansmann et al. 1992), we regard $\mathcal{K}$ as an a priori unknown parameter and estimate an effective, height-independent value of $\mathcal{K}$ by choosing a lower reference altitude range $\left[z_{b}-\Delta z_{b} / 2, z_{b}+\Delta z_{b} / 2\right]$ below the cirrus cloud layer. The Klett equation is iterated with respect to $\mathcal{K}$ until $R=1$ at $\left[z_{b}-\Delta z_{b} / 2, z_{b}+\Delta z_{b} / 2\right]$. If no aerosol- or cloud-free range below the cloud can be found, $\mathcal{K}=0.033 \mathrm{sr}^{-1}$ is used. Details of the iterative method are discussed in the appendix.

For simplicity, we assume that $\mathcal{E}(R)$, the uncertainty of $R$, is dominated by the two leading error sources, the uncertainty $\mathcal{E}(P)$ of lidar signal count rate $P$ and the uncertainty $\mathcal{E}(\mathcal{N})$ of molecular number density $\mathcal{N}$, and use the approximation

$$
\frac{\mathcal{E}(R)}{R} \approx \sqrt{\left[\frac{\mathcal{E}(P)}{P}\right]^{2}+\left[\frac{\mathcal{E}(\mathcal{N})}{\mathcal{N}}\right]^{2}} .
$$

The signal count rate error $\mathcal{E}(P)=\sqrt{P}$ follows from Poisson statistics (e.g., Measures 1984) and $\mathcal{E}(\mathcal{N})$ is estimated from typical rawinsonde temperature and pressure sensor uncertainties of $0.1 \mathrm{~K}$ and $1 \mathrm{hPa}$ above 100 $\mathrm{hPa}$, respectively.
Molecular backscatter coefficients $\beta^{M}$ were calculated from $\mathcal{N}(z)$

$$
\beta^{M}(z, \lambda)=\frac{d \sigma_{\pi}}{d \Omega}(\lambda) \mathcal{N}(z),
$$

where

$$
\mathcal{N}(z)=\frac{p(z)}{k T(z)} .
$$

Here, $d \sigma_{\pi} / d \Omega$ and $k$ denote the differential cross section of molecular backscattering and the Boltzmann constant, respectively. Temperature and pressure profiles, $T(z)$ and $p(z)$, were obtained from daily rawinsonde launches at Vandenberg, California (VBG, $34.65^{\circ} \mathrm{N}$, $\left.120.57^{\circ} \mathrm{W}\right)$. Vandenberg is located about $268 \mathrm{~km}$ northwest of TMF $\left(34.38^{\circ} \mathrm{N}, 117.68^{\circ} \mathrm{W}\right)$. Additionally, pressure and temperature profiles derived from daily $\mathrm{Na}-$ tional Centers for Environmental Prediction (NCEP) analyses were available.

In order to determine whether soundings at Vandenberg (VBG) can be regarded as representative for TMF we compared the four backscatter sonde (BKS) soundings on $11,13,15$, and 18 March 1997 with corresponding rawinsonde launches at VBG, as well as NCEP 


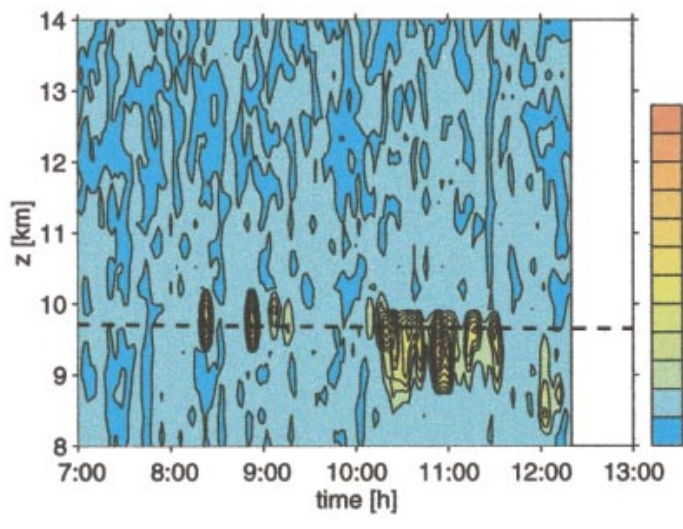

(a)

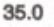

24.5

17.2

12.0

8.4

5.9
4.1

30

2.0

1.4

1.0

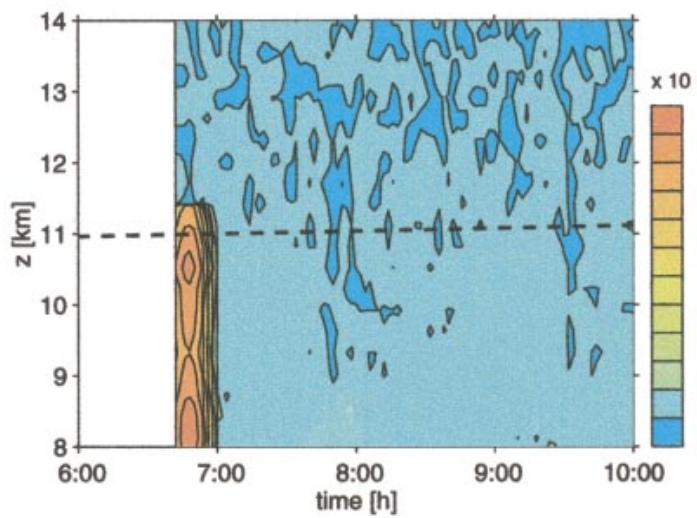

(c)

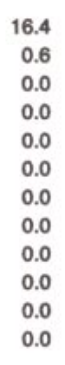

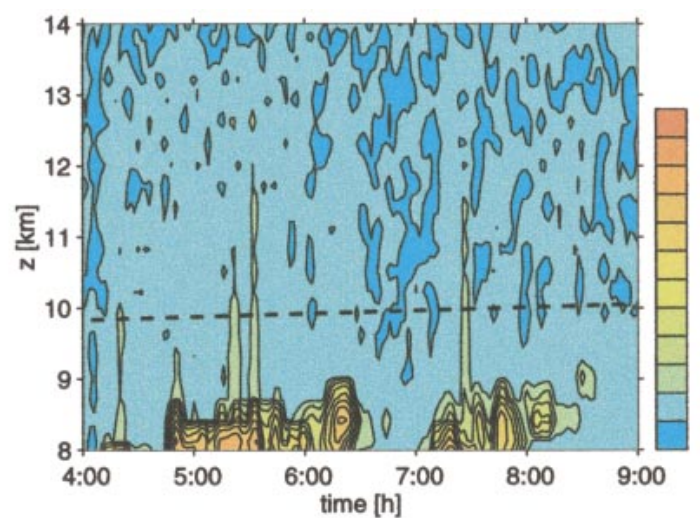

(b)

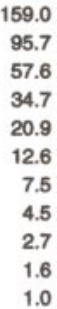

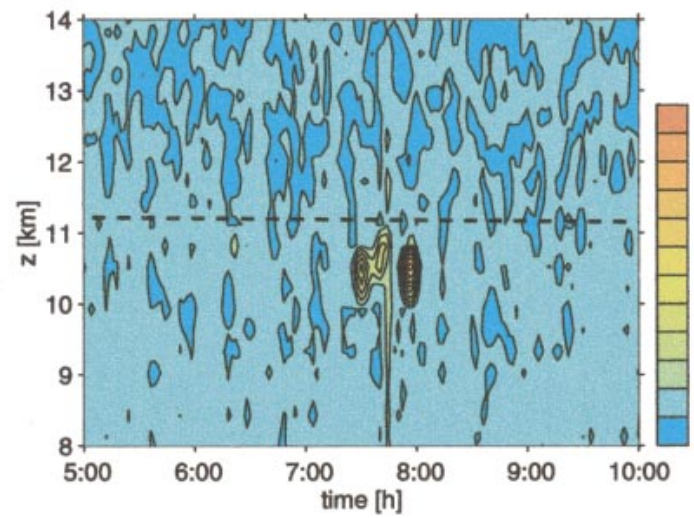

(d)

FIG. 2. Overview of cirrus cloud observations obtained on (a) 3 Mar, (b) 4 Mar, (c) 5 Mar, and (d) 6 Mar 1997. The plots shows the temporal evolution of backscatter ratio at $532 \mathrm{~nm}$ as a function of altitude. The dashed line marks the tropopause altitude as derived from rawinsonde launches at VBG. Times are given in UTC.

analyses. Figure 4 shows the result. The mean temperature differences between BKS and VBG rawinsondes (full lines) and between BKS and NCEP analyses (dashed) are plotted in the right panel. The left panel shows the corresponding relative density differences. Standard deviations of normalized density and temperature differences within the $8-14 \mathrm{~km}$ altitude range are $0.93 \%$ and $1.98 \mathrm{~K}$, respectively. In the lidar data analysis we use VBG temperature and density profiles with $\mathcal{E}(T)$ $=2 K$ and $\mathcal{E}(\mathcal{N}) / \mathcal{N}=1 \%$.

In order to test the validity of approximation Eq. (3) Monte Carlo simulations for a wide range of particulate backscatter coefficients, backscatter-to-extinction ratios and molecular densities have been performed. The simulations show that the iterative Klett algorithm yields similar or better results compared to Klett's method with constant backscatter-to-extinction ratio provided the true backscatter ratio below the cloud does not exceed $\approx 1.1$. For the simulation we set ground-level pressure to $p(z=0 \mathrm{~km})=1013.25 \mathrm{hPa}$ and use a constant scale height of $7 \mathrm{~km}$. A midlatitude temperature profile is taken from the CIRA atmospheric model (Fleming et al. 1990). The cloud layer is simulated by setting $\beta^{P}=$ $5 \times 10^{-6} \mathrm{~m}^{-1} \mathrm{sr}^{-1}$ between 10 and $12 \mathrm{~km}$ yielding a backscatter ratio between 14 and 18 (cf. Fig. 5). Here
$\mathcal{K}$ is varied following a Gaussian distribution with mean value of $0.067 \mathrm{sr}^{-1}$ and standard deviation of $0.033 \mathrm{sr}^{-1}$. In order to study the effect of aerosol occurrence below the cloud layer the simulated backscatter ratio below $z$ $=10 \mathrm{~km}$ changes between 1 and 1.1 with a uniform random distribution. (In the retrieval $R=1$ at the lower reference altitude range is assumed.)

As an example one of the retrieved profiles (solid line) together with the corresponding simulated backscatter ratio (dashed) is shown in Fig. 5 (left panel). The right panel of Fig. 5 shows the uncertainty of $R$ calculated according to Eq. 3 (solid) and the norm of the difference between true and retrieved backscatter ratio, $\Delta=\left|R_{\text {true }}-R\right|$, (dashed). The norm, $\Delta$, averaged over 100 simulations, is plotted as a dotted line. In general we find that the error calculated according to Eq. (3) agrees with the true uncertainty within 50\%. The systematically smaller error above the cloud is caused by the normalization $R\left(z_{t}\right)=1$, which is not taken into account in Eq. (3).

We note that the retrieved and true cloud optical depths

$$
\tau\left(z_{b}, z_{t}\right)=\int_{z_{b}}^{z_{t}} \sigma^{P}(z) d z
$$



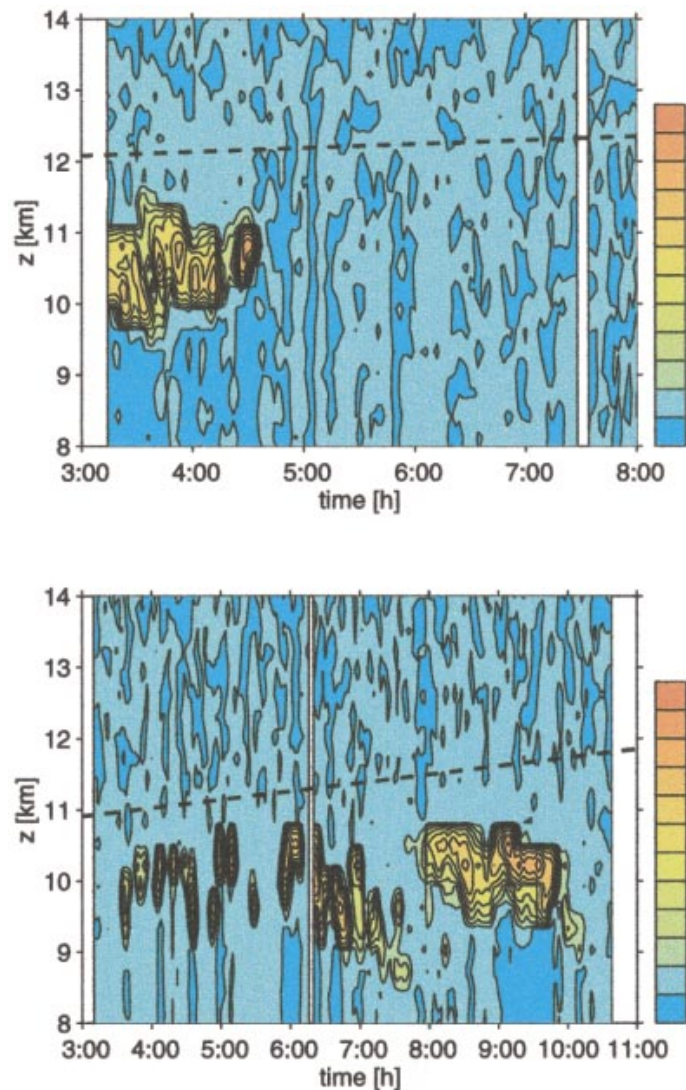

(a)

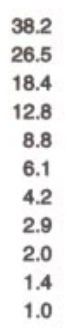

(c)

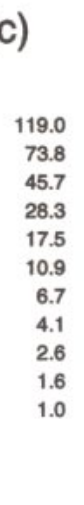

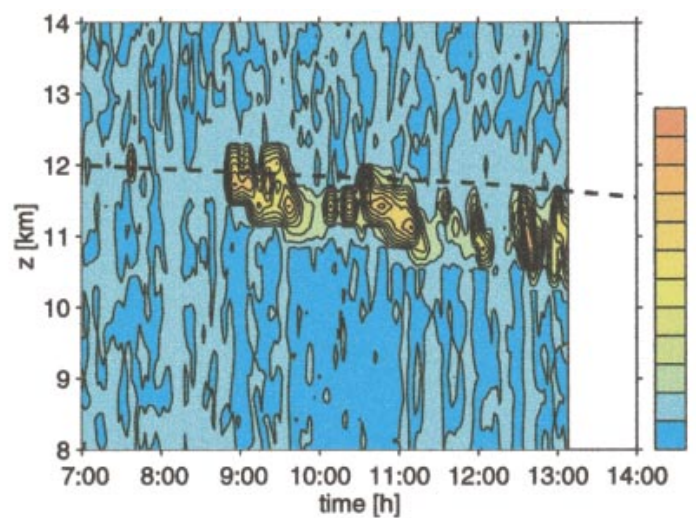

(b)

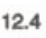

9.6

9.6
7.5

5.8

5.8
4.5
3.5

3.5

2.7

2.1

1.2

1.0

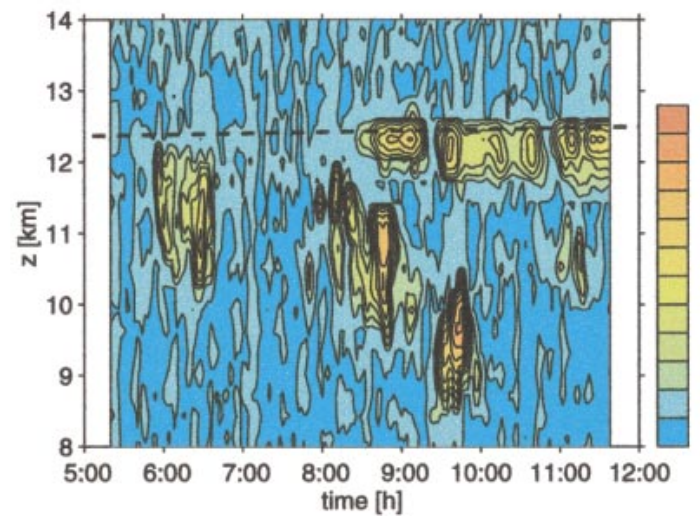

(d)

105.4

66.1

41.5

16.3

10.2

6.4

4.0

2.5

1.5
1.0

FIG. 3. Overview of cirrus cloud observations obtained on (a) 10 Mar, (b) 11 Mar, (c) 12 Mar, and (d) 13 Mar 1997. The plots show the temporal evolution of backscatter ratio at $532 \mathrm{~nm}$ as a function of altitude. The dashed line marks the tropopause altitude as derived from rawinsonde launches at VBG. Times are given in UTC.
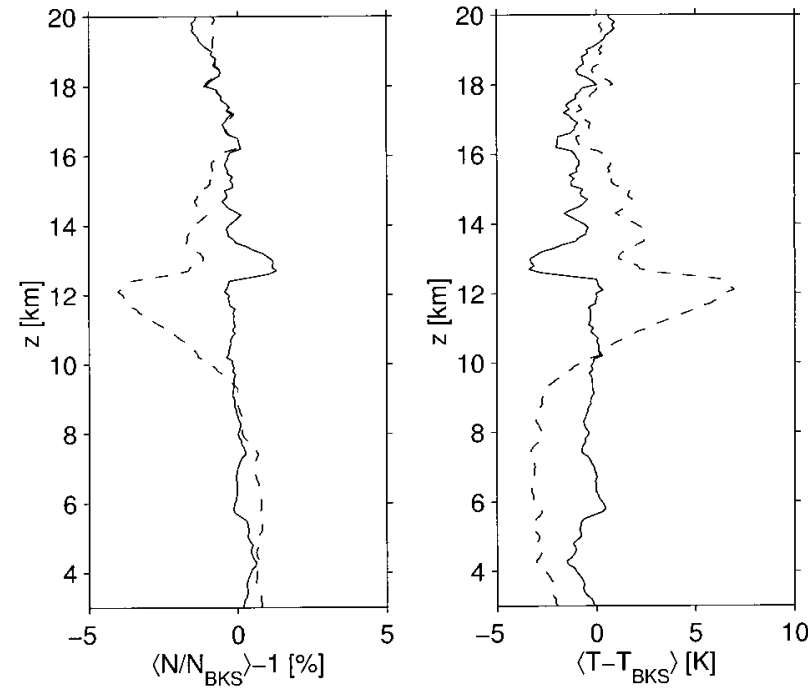

FIG. 4. The averaged normalized (left) density deviations and (right) temperature deviations between BKS and VBG rawinsondes (full lines), and BKS and NCEP analyses (dashed).
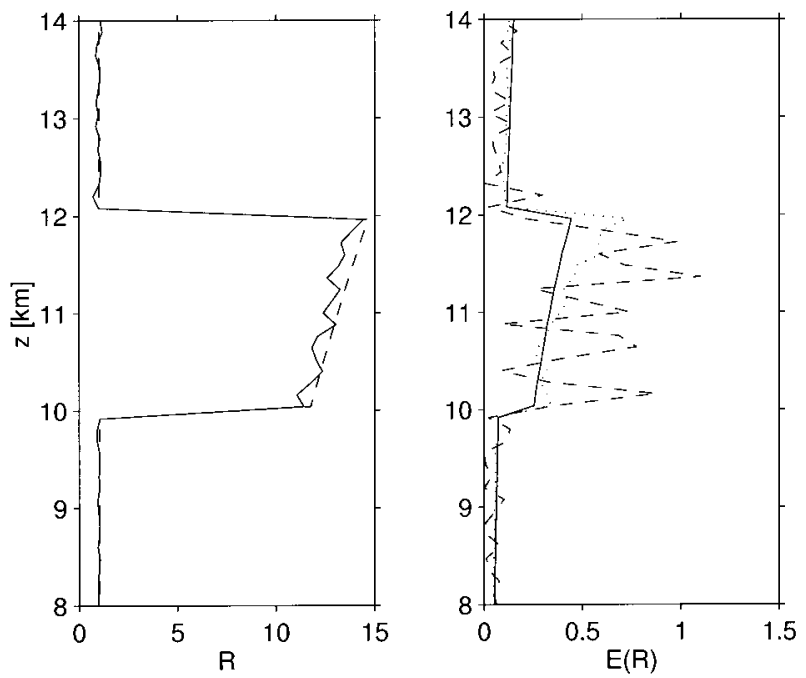

FIG. 5. Monte Carlo simulation of iterative Klett algorithm. (left) The solid line marks one example of a backscatter ratio retrieved in the simulation; the dashed line is the true backscatter ratio profile. (right) The uncertainty of $R$ calculated according to Eq. (3) (solid) and the mean difference between true and retrieved backscatter ratio (dashed). For details see text. 


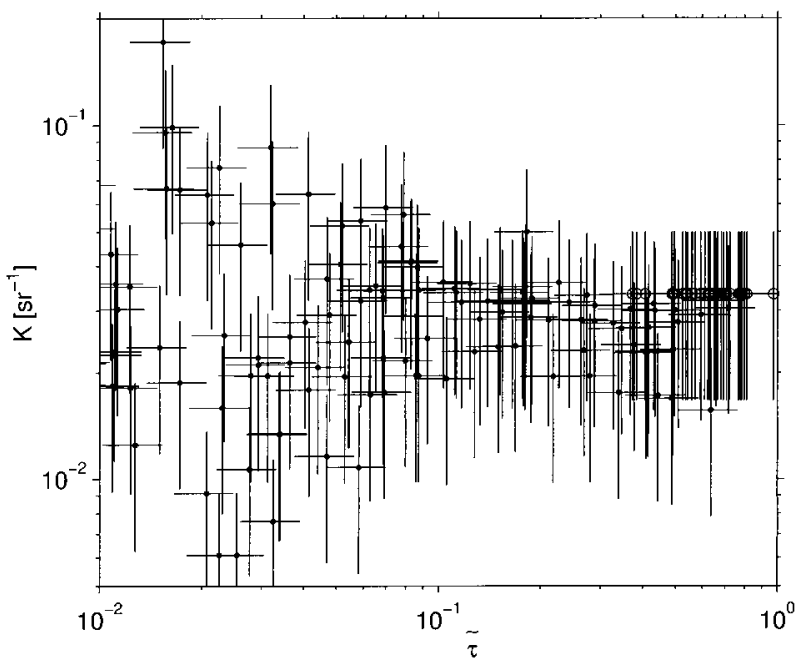

FIG. 6. Relation between cloud optical depth $\tilde{\tau}$ and backscatter-toextinction ratio $\mathcal{K}$ at $532 \mathrm{~nm}$ derived from MARL measurements. Cases in which the iterative Klett algorithm could not be used and $\mathcal{K}=0.033 \mathrm{sr}^{-1}$ was assumed are shown as open symbols.

between $z_{b}=7 \mathrm{~km}$ and $z_{t}=16 \mathrm{~km}$ of the simulation shown in Fig. 5 are 0.178 and 0.152 , respectively. The difference of about $17 \%$ is significantly smaller than the $50 \%$ standard deviation of $\mathcal{K}$ used in the simulation. Our retrieval algorithm does not take into account multiplescattering processes (Eloranta 1998; Sassen and Petrilla 1986; Wandinger et al. 1994). In general, the iterative algorithm allows for the estimation of the altitude independent backscatter-to-extinction ratio within $\approx 20 \%$ uncertainty provided multiple scattering processes can be ignored, that is, the cloud optical depth is small compared to unity; $\mathcal{E}(\mathcal{K}) / \mathcal{K}=20 \%$ is used in the data analysis.

MARL detects elastic backscattering $P(z, \lambda)$ as well as $N_{2}$ Raman inelastic backscattering $P\left(z, \lambda^{R}\right)$ at 532 and $355 \mathrm{~nm}$. Here, $\lambda^{R}=\left(\lambda^{-1}-2329.66 \mathrm{~cm}^{-1}\right)^{-1}$ denotes the $N_{2}$ Raman shifted wavelength. Within the single-scattering approximation backscatter ratio can also be calculated using $P\left(z, \lambda^{R}\right)$ according to

$R(z)=K_{R} \frac{P(z, \lambda)}{P\left(z, \lambda^{R}\right)} \exp \int_{z_{s}}^{z}\left[\sigma^{M}(\tilde{z}, \lambda)-\sigma^{M}\left(\tilde{z}, \lambda^{R}\right)\right] d \tilde{z}$,

where $\sigma^{M}$ and $z_{s}$ denote the extinction coefficient of molecular scattering and the lidar altitude, respectively. The constant $K_{R}$ is determined by normalizing $R$ to unity at an altitude range between 13 and $16 \mathrm{~km}$ since no cirrus cloud layers were observed above $13 \mathrm{~km}$ during the campaign.

From inelastic backscatter data cloud optical depth $\tau\left(z_{b}, z_{t}, \lambda\right)$ between altitudes $z_{b}$ and $z_{t}$ is calculated according to

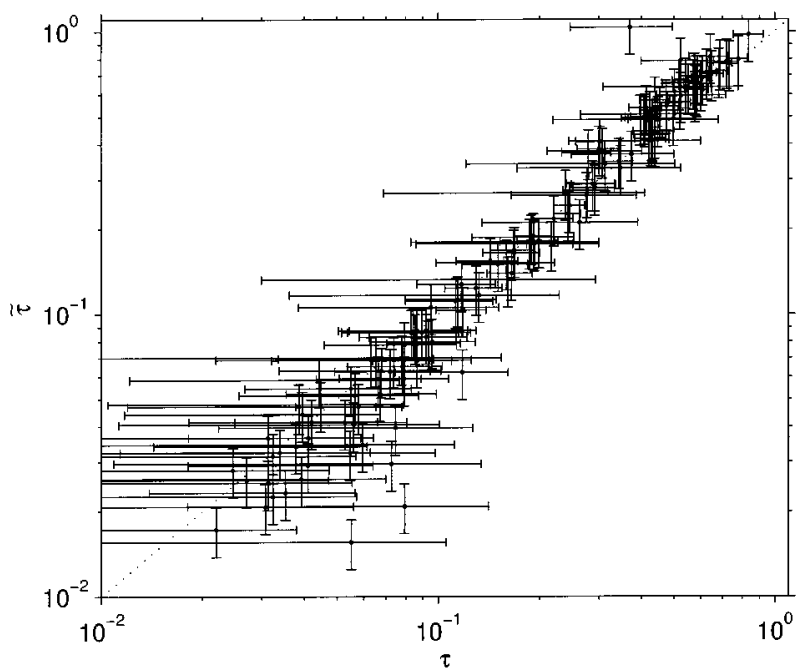

FIG. 7. Correlation between cloud optical depth $\tau$ derived from Klett's algorithm and cloud optical depth $\tilde{\tau}$ obtained by the Raman method. For details see text.

$$
\begin{aligned}
\tau\left(z_{b}, z_{t}, \lambda\right)= & \frac{1}{2} \ln \left[\frac{P\left(z_{b}, \lambda^{R}\right)\left(z_{b}-z_{s}\right)^{2}}{P\left(z_{t}, \lambda^{R}\right)\left(z_{t}-z_{s}\right)^{2}} \frac{\mathcal{N}\left(z_{t}\right)}{\mathcal{N}\left(z_{b}\right)}\right] \\
& -\frac{1}{2} \int_{z_{b}}^{z_{t}}\left[\sigma^{M}(\lambda)+\sigma^{M}\left(\lambda^{R}\right)\right] d z \\
\mathcal{E}\left[\tau\left(z_{b}, z_{t}, \lambda\right)\right] \approx & {\left[\left(\frac{\mathcal{E}\left[P\left(z_{b}\right)\right]}{4 P\left(z_{b}\right)}\right)^{2}+\left(\frac{\mathcal{E}\left[P\left(z_{t}\right)\right]}{4 P\left(z_{t}\right)}\right)^{2}\right.} \\
& \left.+\left(\frac{\mathcal{E}\left[\mathcal{N}\left(z_{b}\right)\right]}{4 \mathcal{N}\left(z_{b}\right)}\right)^{2}+\left(\frac{\mathcal{E}\left[\mathcal{N}\left(z_{t}\right)\right]}{4 \mathcal{N}\left(z_{t}\right)}\right)^{2}\right]^{1 / 2} .
\end{aligned}
$$

Alternatively, assuming backscatter-to-extinction ratio $\mathcal{K}$ is known, optical depth $\tau\left(z_{b}, z_{t}, \lambda\right)$ and its uncertainty can be approximated by

$$
\begin{gathered}
\tilde{\tau}\left(z_{b}, z_{t}, \lambda\right)=\frac{1}{\mathcal{K}} \int_{z_{b}}^{z_{t}} \beta^{P}(z) d z \\
\mathcal{E}\left[\tilde{\tau}\left(z_{b}, z_{t}, \lambda\right)\right] \approx \tilde{\tau}\left(z_{b}, z_{t}, \lambda\right) \frac{\mathcal{E}(\mathcal{K})}{\mathcal{K}} .
\end{gathered}
$$

The comparison of $\tau$ with $\tilde{\tau}$ derived from all MARL observations at $532 \mathrm{~nm}$ is shown in Fig. 7. Only observations with uncertainties $\mathcal{E}(\tau)$ less than $100 \%$ are plotted. With the exception of one data point there is agreement between $\tau$ and $\tilde{\tau}$ on the one-sigma-level showing that Klett's algorithm and the Raman method produce consistent cloud optical depths. At optical depths exceeding 0.1 the slope increases to $1.20 \pm 0.04$. This bias is most likely caused by underestimating $\beta^{P}\left(z_{b}\right)$ below the cloud by imposing $R\left(z_{b}\right)=1$.

The dependency of $\mathcal{K}$ on cloud optical depth is shown in Fig. 6. Based on MARL 532-nm data we find back- 
scatter-to-extinction ratios between about $0.02 \mathrm{sr}^{-1}$ and about $0.05 \mathrm{sr}^{-1}$. However, in particular for low optical depth clouds variations of $\mathcal{K}$ by more than an order of magnitude are observed. For most optically thick clouds the iterative Klett algorithm could not be used since no cloud-free 2-km range between 5 and $13 \mathrm{~km}$ was found. In those cases $\mathcal{K}=0.033 \mathrm{sr}^{-1}$ has been used (open symbols in Fig. 6). Again we note that in optical thick clouds multiple scattering dominates, which is not taken into account by our analysis.

Due to statistical errors of the inelastic backscatter signals $P\left(z, \lambda^{R}\right)$, uncertainties of optical depth below 0.01 exceed $100 \%$ in all observed cases. However, analysis of the polarization state of the backscattered signals allows for the detection of cirrus layers even for $\tau \leq$ 0.01 . Volume depolarization is defined by the ratio of the count rates in the aligned- and cross-polarized detection channels,

$$
\begin{aligned}
\delta(z, \lambda) & =K_{\delta} \frac{P_{\perp}(z, \lambda)}{P_{\|}(z, \lambda)} \\
\frac{\mathcal{E}(\delta)}{\delta} & =\left[\left(\frac{\mathcal{E}\left(P_{\perp}\right)}{P_{\perp}}\right)^{2}+\left(\frac{\mathcal{E}\left(P_{\|}\right)}{P_{\|}}\right)^{2}\right]^{1 / 2} .
\end{aligned}
$$

The constant $K_{\delta}$ follows from normalization of $\delta$ to $\delta^{M}$ at a cloud-free altitude range between 13 and $16 \mathrm{~km}$. Depending on interference filter width in the receiver channel the value of $\delta^{M}$ varies between 0.0035 and 0.0141 (Young 1980). For the filter FWHM used in MARL and TAL (see Table 1), we used $\delta^{M}=0.0136$ and $\delta^{M}=0.0045$, respectively.

\section{b. Backscatter sonde data analysis}

The basic backscatter data of the BKS instrument is a peak voltage level measured and recorded after each triggering of the flash tube. In the analysis the backscatter ratio was determined by dividing the measured peak value by the calculated peak voltage for aerosolfree air at the ambient pressure and temperature. The response of the instrument at ground level pressure and temperature conditions was determined through calibration with an ensemble of four standard backscatter sondes maintained at Laramie, or by direct measurement in a clean air tower.

For the low aerosol conditions encountered during the flights it was necessary to identify any sensitivity drift (as could be induced by the extreme environmental temperature and pressure conditions) and make necessary corrections if needed. Any drift was easily detected by comparison of ascent and descent data.

For low aerosol conditions sources of errors and uncertainties need to be considered. The repeatability of any given calibration is about $1 \%$. In addition, a typical $2 \%$ drift in calibration may occur during shipment of the sonde. However, in this case the sondes were personally escorted and probably did not experience a sudden change in calibration due to mishandling. If cor-
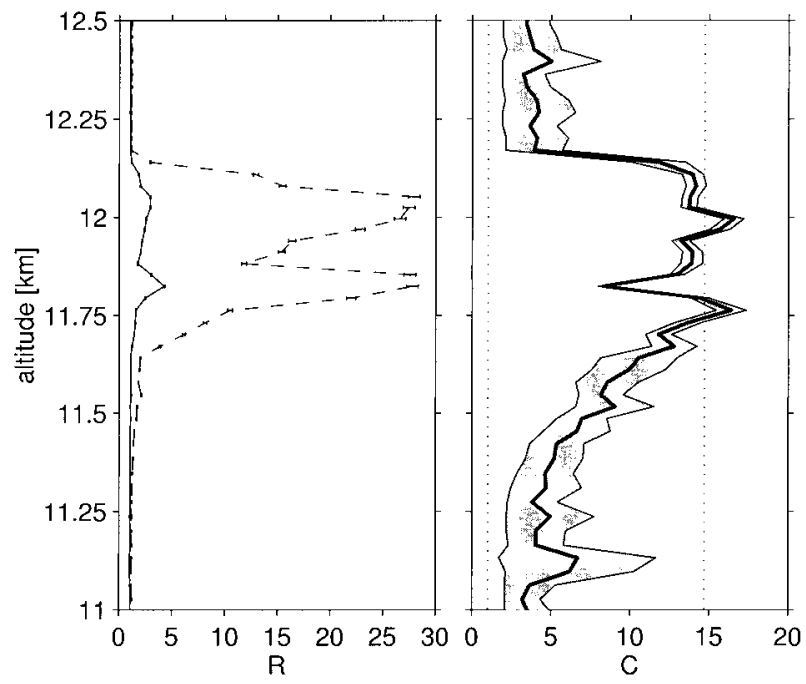

FIG. 8. (left) altitude profiles of backscatter ratio at wavelengths of $490 \mathrm{~nm}$ (solid line) and $940 \mathrm{~nm}$ (dashed) derived from BKS flight 1 (11 Mar 1997). The right panel shows the corresponding color ratio profile (full line). The shaded area marks the one-sigma-standard deviation. Dotted lines indicate the color ratio values of molecular scattering $(C=1)$ and large particle limit $(C=14.7)$, respectively.

rections to drift are necessary, this could lead to an additional uncertainty or $1 \%$ or $2 \%$. There is a small residual signal from light scattered by parts of the instrument package back into the photometers. For the altitudes of interest here this effect was about $1 \%$ or less. The absolute calibration was thought to be accurate to $1 \%$ or $2 \%$. Thus, the typical root-mean-square uncertainty in a typical sounding may be $2 \%$ to $3 \%$. Certainly, $\pm 2 \%$ is the best that could reasonably be expected from the backscatter sonde. Unfortunately, even such a small uncertainty can lead to a relatively large uncertainty for low aerosol conditions. For example, if the backscatter ratio is 1.08 , the aerosol backscatter ratio would be 0.08 and the $2 \%$ uncertainty suggested above now translates to a $25 \%$ uncertainty in the aerosol backscatter ratio.

During the first two BKS flights on 11 March and 13 March 1997 the sondes passed cirrus clouds. The backscatter ratio profiles observed during ascent of flight 1 is plotted in Fig. 8. The 490- and 940-nm profiles show two distinct cirrus layers separated by less than $300 \mathrm{~m}$.

We express the wavelength dependence of particulate backscattering in terms of color ratio $C$, which is defined by

$$
C_{\lambda_{1}, \lambda_{2}}(z)=\frac{R\left(z, \lambda_{1}\right)-1}{R\left(z, \lambda_{2}\right)-1}=\frac{\beta^{P}\left(z, \lambda_{1}\right)}{\beta^{P}\left(z, \lambda_{2}\right)}\left(\frac{\lambda_{2}}{\lambda_{1}}\right)^{-4.13} .
$$

In the right panel of Fig. $8 C_{\lambda_{1}, \lambda_{2}}(z)$ is plotted for $\lambda_{1}=$ 940 and $\lambda_{2}=490 \mathrm{~nm}$. Vertical dotted lines mark the color ratio values for Rayleigh scattering $\left[C_{940 \mathrm{~nm} / 490 \mathrm{~nm}} \approx\right.$ $\left.(490 \mathrm{~nm} / 940 \mathrm{~nm})^{0}=1\right]$ and scattering in the geometrical optics approximation $\left[C_{940 \mathrm{~nm} / 490 \mathrm{~nm}} \approx(490 \mathrm{~nm} / 940\right.$ 
TABLE 4. Occurrences of visible $(\tau>0.03)$ and subvisible $[\tau \leq$ 0.03 and $\left.\delta>\delta^{M}+10 \cdot \mathcal{E}(\delta)\right]$ cirrus between 8 and $13-\mathrm{km}$ altitude during the campaign. The data was derived from MARL observations at $532 \mathrm{~nm}$.

\begin{tabular}{lcc}
\hline \hline & No. events & Percentages \\
\hline Clear sky & 684 & $49.3 \%$ \\
Subvisible cirrus & $563_{-96}^{+38}$ & $40.6 \% \%_{-6.9 \%}^{+2.7 \%}$ \\
Visible cirrus & $140_{-38}^{+96}$ & $10.1 \%_{-2.7 \%}^{+6.9 \%}$ \\
Total & 1387 & $100 \%$ \\
\hline
\end{tabular}

$\left.\mathrm{nm})^{-4.13}=14.7\right]$. The color ratio for the lidar measurements will be treated in section 4 .

\section{Discussion}

The lidar and backscatter sonde measurements fall in three broad categories (cf. Figs. 1-3). First, homogeneous cloud layers with maximum backscatter ratios of about 100 and optical depths of $0.3-1$ (both at $532 \mathrm{~nm}$ ) were observed. The observations on 27 February belong to this class. Second, individual cloud systems (often clearly separated from each other) with $R \approx 5-100$ and $\tau \lesssim 0.3$ were detected. Third, clear sky prevailed on 10 of 25 nights, that is, no clouds were found within the instruments' detection limits.

For the following discussion, cirrus clouds with an cloud optical depth $\tau<0.03$ at $532 \mathrm{~nm}$ will be referred to as subvisible cirrus (Sassen et al. 1989). Since the uncertainty of $\tau$ is on the order of 0.01, typically, distinction between clear sky and subvisible cirrus is impossible on the basis of optical depth alone. We utilize volume depolarization - a sensitive indicator for ice particle presence-to discern subvisible clouds from clearsky observations (Platt et al. 1987; Sassen et al. 1989). Subvisible cirrus is discriminated against clear sky by requiring low optical depth of $\tau<0.03$ and enhanced values of volume depolarization, $\delta(z)>\delta^{M}+10 \mathcal{E}[\delta(z)]$. Here, $\mathcal{E}(\delta)$ denotes the uncertainty of $\delta$.

The occurrence frequencies for subvisible and visible clouds obtained in this manner are listed in Table 4. The uncertainties quoted in Table 4 were derived by replacing the subvisibility threshold by $\tau<0.03+\mathcal{E}(\tau)$ and $\tau<0.03-\mathcal{E}(\tau)$ where $\mathcal{E}(\tau)$ is the uncertainty of $\tau$.

On the basis of 1387 individual profiles observed by MARL we find in 703 cases $(51 \%)$ signatures for the presence of cirrus. A large fraction (563 cases or about $80 \%$ ) of these clouds are subvisible.

On the basis of lidar backscatter and depolarization profiles cirrus we studied cloud-top heights $z_{\mathrm{CT}}$ and characterized cloud geometries with high temporal and vertical resolution. Here, $z_{\mathrm{CT}}$ is defined as the maximum altitude that satisfies the relations

$$
\begin{aligned}
& \delta(z)>\delta^{M}+10 \mathcal{E}[\delta(z)] \text { and/or } \\
& R(z)>1+10 \mathcal{E}[R(z)]
\end{aligned}
$$

at $532 \mathrm{~nm}$. Figure 9 shows histograms of $z_{\mathrm{CT}}$ derived from all MARL observations. The occurrence distri-
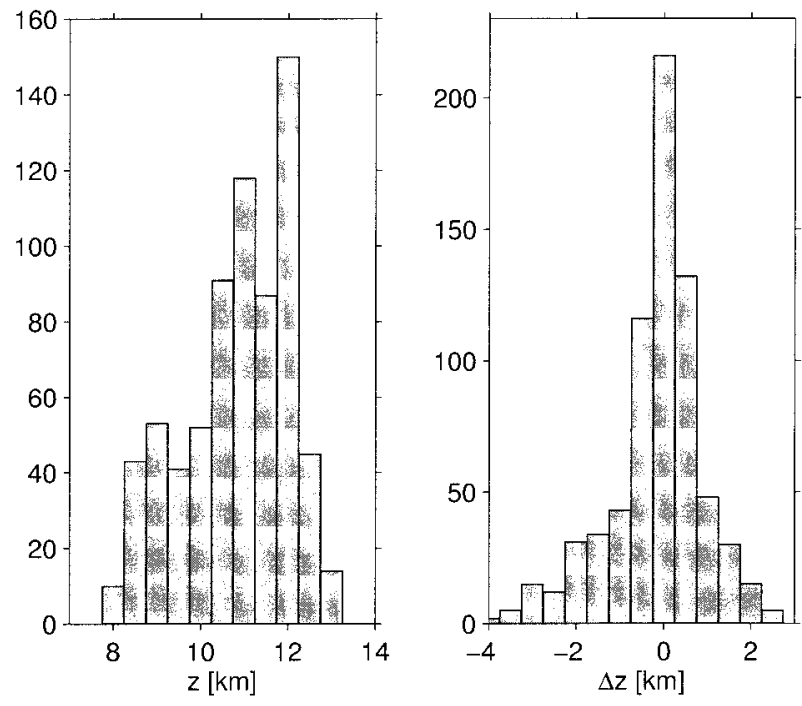

FIG. 9. Cirrus cloud-top heights derived from MARL observations. (Left) Histogram distribution of cirrus cloud-top heights. (right) Histogram distribution of cloud-top heights above the tropopause altitude. Tropopause altitudes are taken from VBG rawinsonde profiles. For details see text.

bution of $z_{\mathrm{CT}}$ is plotted in the left panel. Similarly, the right panel shows the occurrence distribution of $z_{\mathrm{CT}}-$ $z_{\mathrm{TP}}$. Tropopause heights $z_{\mathrm{TP}}$ were derived from VBG rawinsonde data. The standard deviations are $1.23 \mathrm{~km}$ (left) and $1.06 \mathrm{~km}$ (right), respectively. The difference between former and latter underlines that the clouds tend to occur at the tropopause altitude. Figure 9 (right panel) suggests that some cloud layers are found in the lower stratosphere. However, by comparing tropopause altitudes derived from the four BKS soundings with VGB rawinsonde data we find that the rawinsondes tropopause levels underestimate the true tropopause at TMF by 250-350 m. Comparison with NCEP data yields an even larger difference of almost $400 \mathrm{~m}$. While 363 of 704 observations $(52 \%)$ result in clouds tops above the tropopause, assuming an underestimation by $400 \mathrm{~m}$ reduces the fraction to $21 \%$ (145 of 704). An offset of $300 \mathrm{~m}$ yields $27 \%$ (193 of 704).

We determine vertical and horizontal extents of the observed cloud systems in the following way. For each individual backscatter ratio profile the FWHM is calculated. If the maximum value of $R$ is below a threshold value of 1.1 the corresponding FWHM is discarded. The same procedure is applied on each altitude level for contiguous datasets yielding horizontal cloud extents. For the purpose of this analysis datasets separated by gaps of less than $30 \mathrm{~min}$ are still considered contiguous. The results are shown as histograms in Fig. 10 for the vertical (top panel) and horizontal (bottom panel) length scales, $\mathrm{FWHM}_{v}$ and $\mathrm{FWHM}_{h}$. The latter have been converted to geometrical length using wind velocity data derived from VBG rawinsonde profiles. The mean values of $\mathrm{FWHM}_{v}$ and $\mathrm{FWHM}_{h}$ are $0.31 \mathrm{~km}$ and $7.5 \mathrm{~km}$, respectively. 

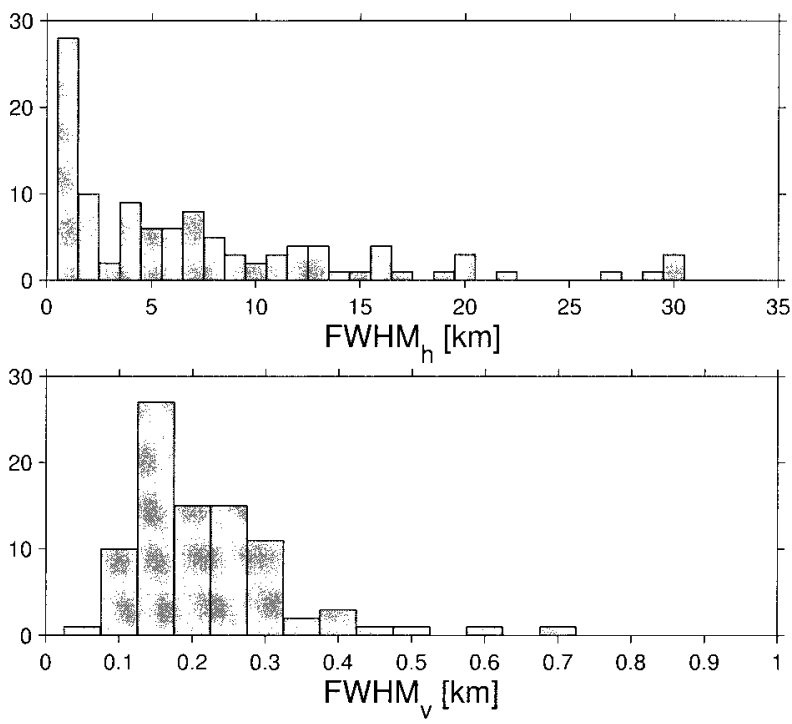

FIG. 10. Vertical and horizontal length scales of cirrus clouds derived from MARL 532-nm observations.

Together with cloud-top heights and spatial cloud characteristics, effective particle radii $r_{e}$ also determine the radiative properties of cirrus clouds (e.g., Stephens et al. 1990). From remote-sensing and in situ studies it is known that a wide range of particle radii between a few tens of microns and several hundreds of microns occur within cirrus clouds (e.g., Heymsfield and Platt 1984; Platt et al. 1987, 1989; Ström et al. 1994; Gayet et al. 1996). Within the geometrical optics size range, $\left(r_{e} \gg \lambda\right)$, particulate backscatter and extinction coefficients are wavelength independent (Bohren and Huffman 1983). In this case color ratios are expected to approach the value $C_{940 \mathrm{~nm} / 490 \mathrm{~nm}}=14.7(\mathrm{BKS})$ and $C_{532 \mathrm{~nm} / 355 \mathrm{~nm}}=5.32$ (lidar), respectively. However, in the measurements we find significant deviation from these values indicating the presence of smaller particle sizes. For example, the profile shown in Fig. 8 (right panel) falls significantly below $C_{940 \mathrm{~nm} / 490 \mathrm{~nm}}$ within a thin layer at $11.8 \mathrm{~km}$ altitude and below $11.6 \mathrm{~km}$ indicating the occurrence of smaller particles primarily at the cloud bottom.

Lidar observations show deviations from the large particle color ratio $C_{532 \mathrm{~nm} / 355 \mathrm{~nm}}=5.32$ as well. In Fig. 11 (right panel) a color ratio profile derived from MARL observations on 27 February 1997 at 0416 UTC and the corresponding backscatter ratio profiles (left panel) are plotted. Large particles seem to dominate within the observed cirrus layer. However, at 10.6-km altitude significant deviations in color ratio indicate the presence of smaller particles.

The occurrence distribution of $C_{532 \mathrm{~nm} / 355 \mathrm{~nm}}$ is shown in Fig. 12 (bottom panel). A threshold condition of $R_{355 \mathrm{~nm}}>1.1$ and $R_{532 \mathrm{~nm}}>1.1$ is imposed within the altitude range $8-13 \mathrm{~km}$. In the top panel 1936 color ratio measurements are plotted as a function of back-

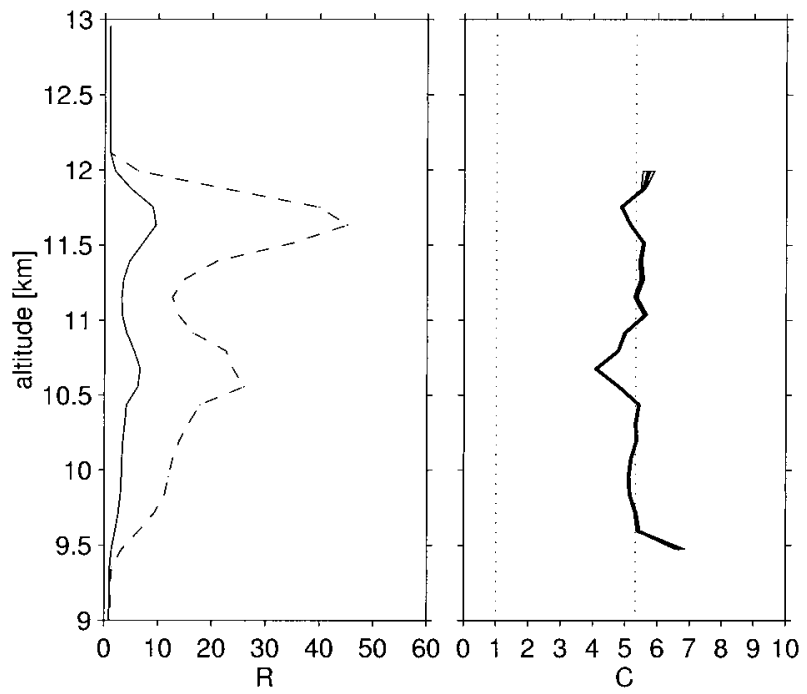

FIG. 11. (left) Altitude profiles of backscatter ratio at wavelengths of $355 \mathrm{~nm}$ (solid line) and $532 \mathrm{~nm}$ (dashed) derived from MARL observations at 0416 UTC 27 Feb 1997. (right) The corresponding color ratio profile (full line). Dotted lines indicate the color ratio values of molecular scattering $(C=1)$ and large particle limit $(C=$ 5.32), respectively.

scatter ratio at $532 \mathrm{~nm}$. Color ratio values around 5.3 occur most frequently; however, $18 \%$ of the observed color ratios deviate from $C_{532 \mathrm{~nm} / 355 \mathrm{~nm}}$ by more than $20 \%$. Values outside of the range $\left[C_{532 \mathrm{~nm} / 355 \mathrm{~nm}}-1, C_{532 \mathrm{~nm} / 355 \mathrm{~nm}}\right.$ $+1]$, which are inconsistent with geometrical optics, might indicate the presence of small particles. However, it should be noted that multiple scattering effects cause changes in the observed color ratios as well (Ansmann et al. 1992; Eloranta 1998). The correlation of $C$ with
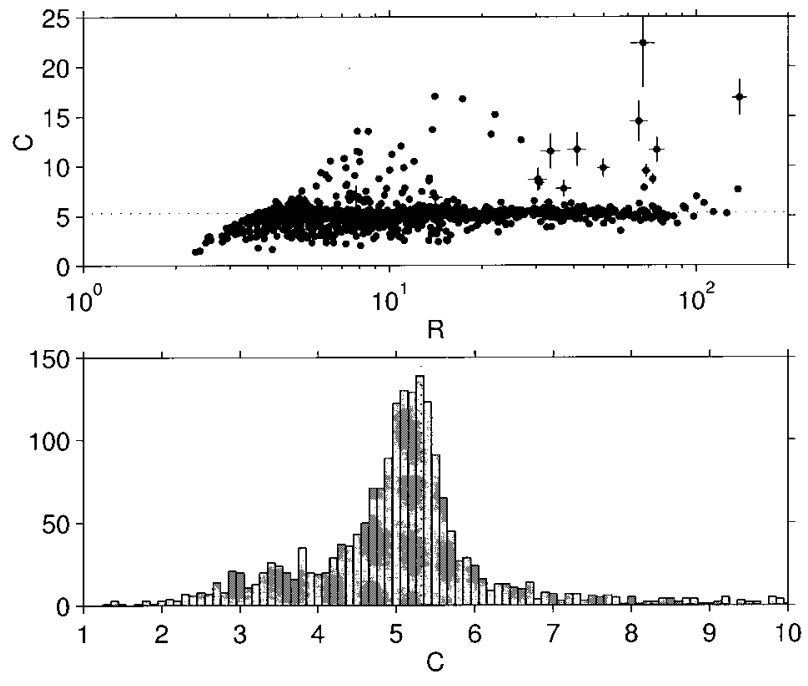

FIG. 12. (top) Color ratio $C$ as a function of backscatter ratio at $532 \mathrm{~nm}$ derived from MARL data. Only data points with $R_{355 \mathrm{~nm}}>$ 1.1 and $R_{532 \mathrm{~nm}}>1.1$ are shown. (bottom) The occurrence distribution of $C$. The dotted lines mark $C=5.32$, the color ratio value expected for large particles. 


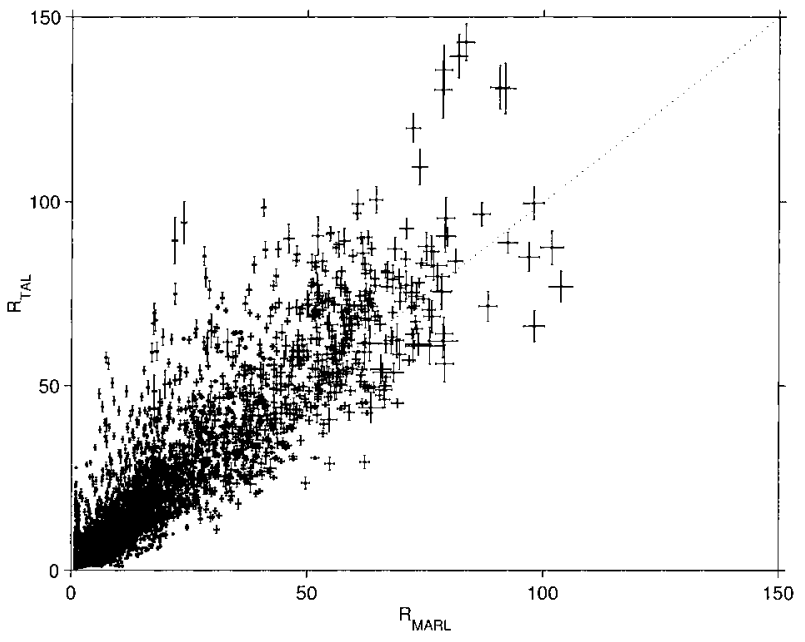

FIG. 13. Correlation between backscatter ratio observed by MARL and TAL on 27 Feb 1997. Linear correlation coefficient is 0.927 with significance 0 . The dotted line marks $R_{\mathrm{MARL}}=R_{\mathrm{TAL}}$.

backscatter ratio at $532 \mathrm{~nm}$ suggests that color ratio deviate from $C_{532 \mathrm{~nm} / 355 \mathrm{~nm}}$ primarily at $R \lesssim 10$.

Finally, we discuss the aspect of instrument intercomparison following two approaches. First, for the comparison between TAL and MARL high-temporalresolution observations, both lidars' backscatter ratio profiles were interpolated on an altitude grid of $120 \mathrm{~m}$ and a temporal resolution of $1 \mathrm{~min}$. Second, time periods were selected during which the lidars operated simultaneously and mean profiles averaged over these time intervals are intercompared.

In Fig. 13 the correlation of backscatter ratios measured between 4:30 and 8:00 UTC on 27 February 1997 by MARL and TAL is shown. We have selected this measurement night since during that period a homogeneous cirrus layer was observed for several hours (cf. Fig. 1c). The mean value of the ratio $R_{\mathrm{MARL}} / R_{\mathrm{TAL}}$, $\left\langle R_{\mathrm{MARL}} / R_{\mathrm{TAL}}\right\rangle$, is 1.02 with a standard deviation of 0.49 . Thus, within the uncertainties there exists no bias toward one of the two instruments. The large standard deviation is indicative of the substantial small-scale variability of the observed cloud layers despite its homogeneous appearance. During the other intercomparison intervals more isolated cloud systems were observed and $\left\langle R_{\mathrm{MARL}} / R_{\mathrm{TAL}}\right\rangle$ deviates significantly from unity with values ranging from 0.86 to 1.16 . A bias toward one instrument could not be found.

By integration of measurements over (almost) identical periods of time backscatter ratio profiles of ATlidar, MARL, and TAL were calculated. Figure 14 shows backscatter ratio profiles recorded on 27 February (351/355 nm, left panel) and 6 March (532 nm, right). Acceptable agreement between AT-lidar, MARL, and TAL is found for the 27 February observation with mean deviations in 351/355-nm backscatter ratio of about $10 \%$. However, maximum values are on the order of $50 \%$. The differences between backscatter ratio profiles
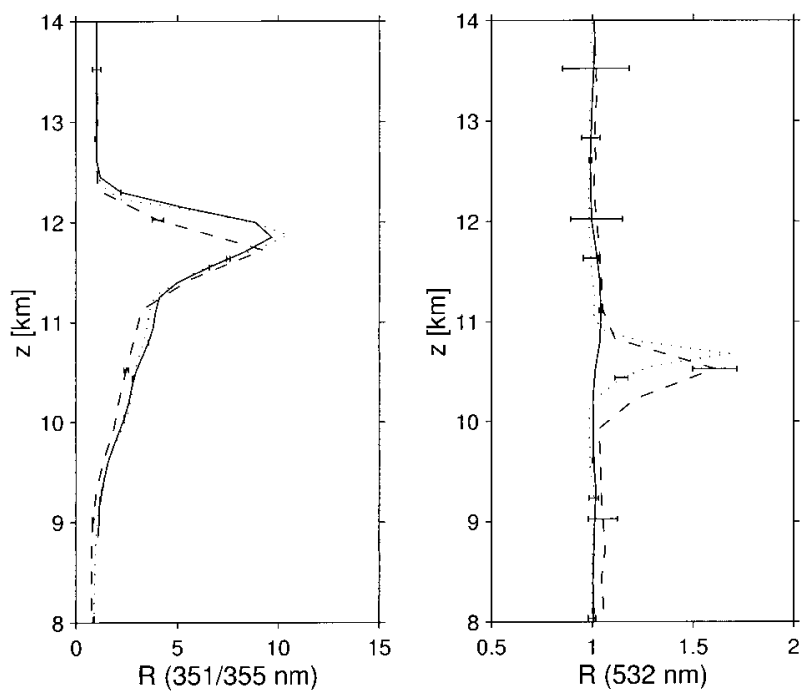

FIG. 14. Comparison of backscatter ratio profiles observed by ATlidar, MARL, and TAL. (left) Backscatter ratio profiles at $351 \mathrm{~nm}$ (AT-lidar, full line) and $355 \mathrm{~nm}$ (MARL, dotted and TAL, dashed line) recorded on $27 \mathrm{Feb}$ 1997. Averaging periods were 0405-0812 (AT-lidar), 0417-0754 (MARL), and 0417-0800 UTC (TAL). (Right) Same for 6 Mar 1997 averaged between 0447-0825, 0448-0812, and 0448-0825 UTC. Note the scale difference between the left and right panels.

of 6 March (right panel) are most likely caused by sampling of different air volumes several hundreds of meters apart and the small-scale character of the cloud systems during that night.

\section{Summary and conclusions}

During STRAIT'97 more than $400 \mathrm{~h}$ worth of lidar data were recorded and four in situ backscatter sonde profiles were obtained. In most cases the observed cirrus belonged to isolated cloud systems; only during one night a homogeneous cirrus layer was observed. For this case a direct intercomparison of 351/355-nm backscatter ratio profiles showed an acceptable agreement on the $10 \%$ level. About $51 \%$ of the observations indicate the presence of cirrus clouds, $80 \%$ of which are subvisual with optical depths below 0.03 at $532 \mathrm{~nm}$. Frequently, cirrus clouds were found close to the tropopause. A simple characterization of the spatial extent of the observed cloud systems yield dimensions of 0.31 and $7.5 \mathrm{~km}$ vertically and horizontally, respectively. We interpret deviations of color ratio from the geometrical optics value as indication for the presence of small particles.

Acknowledgments. We thank E. Eloranta and two anonymous reviewers whose important comments and suggestions strengthened and improved the manuscript significantly. Development and construction of the MARL instrument was funded in part by Deutsche Bundesstiftung Umwelt, Germany. GB thanks the National 
Research Council for the award of an associateship. JMR was supported by the United States National Science Foundation under Grants ATM-95-00186 and OPP-9423285. The work described here was performed at the Jet Propulsion Laboratory, California Institute of Technology, through an agreement with the National Aeronautics and Space Administration. Contribution 1388 of the Alfred Wegener Institute.

\section{APPENDIX}

\section{Klett Inversion Algorithm}

Particulate backscatter coefficients are calculated according to [Klett 1985, Eq. (22)]

$$
\begin{aligned}
\beta^{P}\left(z_{i}\right) & =\frac{Z\left(z_{i}\right)}{\beta^{M}\left(z_{N}\right)^{-1}+2 \Delta z \sum_{j=i}^{N} \mathcal{L} Z\left(z_{j}\right)}-\beta^{M}\left(z_{i}\right) \\
Z\left(z_{i}\right) \equiv \exp \left\{S\left(z_{i}\right)-S\left(z_{N}\right)\right. & \left.-2 \Delta z \sum_{j=i}^{N}\left[\left(\mathcal{L}^{M}-\mathcal{L}\right) \beta^{M}\left(z_{j}\right)+\sigma_{A}^{M}\left(z_{j}\right)\right]\right\} .
\end{aligned}
$$

Here, $z_{i}, i=s, \ldots, N$ denotes the altitude above sea level, $z_{s}$ the instrument's altitude, and $\Delta z \equiv z_{i+1}-z_{i}$ the altitude resolution. Here $S\left(z_{i}\right)=\ln \left[\left(z_{i}-z_{s}\right)^{2} P\left(z_{i}\right)\right]$ is the logarithm of the range-corrected backscattering signal $P\left(z_{i}\right)$ and $\mathcal{L}^{M}=\sigma^{M} / \beta^{M} \approx 8.4$ sr the extinctionto-backscatter ratio of molecular scattering. Absorption due to ozone is taken into account by including the absorption coefficient $\sigma_{A}^{M}\left(z_{i}\right)$.

The lower reference altitude range $\left[z_{b}-\Delta z_{b} / 2, z_{b}+\right.$ $\Delta z_{b} / 2$ ] below the cirrus cloud is found by comparing the observed count rate profile $P\left(z_{i}\right)$ with a modeled count rate profile (Measures 1984)

$$
\begin{aligned}
P_{0}\left(z_{i}\right)= & \frac{K}{\left(z_{i}-z_{s}\right)^{2}} \beta^{M}\left(z_{i}\right) \\
& \times \exp \left\{-2 \sum_{j=s}^{i} \Delta z\left[\sigma^{M}\left(z_{j}\right)+\sigma_{A}^{M}\left(z_{j}\right)\right]\right\}
\end{aligned}
$$

for a particulate-free atmosphere. Here $P_{0}\left(z_{i}\right)$ is fitted to $P\left(z_{i}\right)$ at the ranges $\left[z_{b}(m)-\Delta z_{b} / 2, z_{b}(m)+\Delta z_{b} / 2\right]$ with $\Delta z_{b}=2 \mathrm{~km}$ and $z_{b}(m), m=1, \ldots, M$ varying between 5 - and $12-\mathrm{km}$ altitude. The parameter $K=K(\mathrm{~m})$ is determined for each $m$ separately. The quality of the fit is expressed in terms of the deviation between $P\left(z_{l}\right)$ and $P_{0}\left(z_{l}, m\right)$ within the interval $z_{b}(m)-\Delta z_{b} / 2<z_{l}<$ $z_{b}(m)+\Delta z_{b} / 2$,

$$
\begin{array}{r}
\xi_{m}=\mathcal{S}\left[\frac{P\left(z_{l}\right)-P_{0}\left(z_{l}, m\right)}{P_{0}\left(z_{l}, m\right)}\right] \\
l=b_{0}(m), \ldots, b_{1}(m) .
\end{array}
$$

Here, $S(x)$ denotes the standard deviation of $x$. The lower reference range is taken to be $\left[z_{b}\left(m^{*}\right)-\Delta z_{b} / 2, z_{b}\left(m^{*}\right)\right.$ $\left.+\Delta z_{b} / 2\right]$ where $\xi_{m^{*}}$ denotes the smallest element of the $\xi_{m}, l=b_{0}(m), \ldots, b_{1}(m)$.

The extinction-to-backscatter ratio $\mathcal{L}$ is now computed by minimizing

$$
\chi=\left|\sum_{l=b_{0}\left(m^{*}\right)}^{b_{1}\left(m^{*}\right)} \Delta z \beta^{P}\left(z_{l}, \mathcal{L}\right)\right|
$$

with respect to $\mathcal{L}$ using a scalar bounded nonlinear minimization algorithm (Forsythe et al. 1976). Equation (A1) is used to calculate $\beta^{P}\left(z_{l}, \mathcal{L}\right)$.

In order to guard against events with no particulatefree range interval between 5 - and $12-\mathrm{km}$ altitude, the constraint $\xi_{m^{*}} \leq 10^{-3}$ is imposed. If $\xi_{m^{*}}>10^{-3}$ no minimization is performed and $\mathcal{L}=30 \mathrm{sr}$ is used instead.

\section{REFERENCES}

Ansmann, A., U. Wandinger, M. Riebesell, C. Weitkamp, and W. Michaelis, 1992: Independent measurement of extinction and backscatter profiles in cirrus clouds by using a combined Raman elastic-backscatter lidar. Appl. Opt., 31, 7113-7131.

Bohren, C. F., and D. R. Huffman, 1983: Absorption and Scattering of Light by Small Particles. John Wiley and Sons, 530 pp.

Borrmann, S., S. Solomon, J. E. Dye, and B. Luo, 1996: The potential of cirrus clouds for heterogeneous chlorine activation. Geophys. Res. Lett., 23, 2133-2136.

Eloranta, E. W., 1998: Practical model for the calculation of multiply scattered lidar returns. Appl. Opt., 37, 2464-2472.

Fleming, E. L., S. Chandra, J. J. Barnett, and M. Corney, 1990: International reference atmosphere, chapter 2: Zonal mean temperature, pressure, zonal wind and geopotential height as functions of latitude. Adv. Space Res., 10, 11-59.

Forsythe, G. E., M. A. Malcolm, and C. B. Moler, 1976: Computer Methods for Mathematical Computations. Prentice-Hall, 259 pp.

Gayet, J.-F., G. Febvre, G. Brogniez, H. Chepfer, W. Renger, and P. Wendling, 1996: Microphysical and optical properties of cirrus and contrails: Cloud field study on 13 October 1989. J. Atmos. Sci., 53, 126-138.

Heymsfield, A. J., and C. M. R. Platt, 1984: A parameterization of the particle size spectrum of ice clouds in terms of the ambient temperature and ice water content. J. Atmos. Sci., 41, 846-855.

Klett, J. D., 1985: Lidar inversion with variable backscatter/extinction ratios. Appl. Opt., 24, 1638-1643.

Liou, K. N., 1986: Influence of cirrus clouds on weather and climate processes. Mon. Wea. Rev., 114, 1167-1199.

McDermid, I. S., S. M. Godin, and T. D. Walsh, 1995: Results from the Jet Propulsion Laboratory stratospheric ozone lidar during STOIC 1989. J. Geophys. Res., 100 (D5), 9263-9272.

Measures, R., 1984: Laser Remote Sensing, Fundamentals and Applications. John Wiley and Sons, $510 \mathrm{pp}$.

Platt, C. M. R., J. C. Scott, and A. C. Dilley, 1987: Remote sensing of high clouds. Part VI: Optical properties of midlatitude and tropical cirrus. J. Atmos. Sci., 44, 729-747.

- J. D. Spinhirne, and W. D. Hart, 1989: Optical and microphysical properties of a cold cirrus cloud: Evidence for regions of small ice particles. J. Geophys. Res., 94, 11 151-11 164.

Prabhakara, C., R. S. Fraser, G. Dalu, M. C. Wu, R. J. Curran, and T. Styles, 1988: Thin cirrus clouds: Seasonal distribution over oceans deduced from Nimbus-4 IRIS. J. Appl. Meteor., 27, 379399.

Reichardt, J., A. Ansmann, M. Serwazi, C. Weitkamp, and W. Michaelis, 1996: Unexpectedly low ozone concentrations in mid- 
latitude tropospheric ice clouds: A case study. Geophys. Res. Lett., 23, 1929-1932.

Rosen, J. M., and N. T. Kjome, 1991: Backscattersonde: A new instrument for atmospheric research. Appl. Opt., 30, 1552-1561.

Sassen, K., and R. L. Petrilla, 1986: Lidar depolarization from multiple scattering in marine stratus clouds. Appl. Opt., 25, 14501459 .

— M. K. Griffin, and G. C. Dodd, 1989: Optical scattering and microphysical properties of subvisual cirrus clouds, and climatic implications. J. Appl. Meteor., 28, 91-98.

Schäfer, H.-J., and Coauthors, 1995: A modular and mobile multipurpose lidar system for observation of tropospheric and stratospheric aerosols. SPIE EurOpto Ser., 2581, 128-136.

- O. Schrems, G. Beyerle, B. Hofer, W. Mildner, and F. A. Theopold, 1997: Shipborne measurements with a modular multi-purpose mobile lidar system for tropospheric and stratospheric aerosol observations. SPIE EurOpto Ser., 3104, 265-272.

Singh, U. N., T. J. McGee, and M. R. Gross, 1996: UARS ozone and temperature validation by GSFC lidar during UARS correlative measurement campaigns (1992-1995). Advances in Atmospheric Remote Sensing with Lidar, Selected papers of the 18th International Laser Radar Conference (ILRC), Berlin, 22-26 July 1996, A. Ansmann et al., Eds., Springer, 533-536.

Solomon, S., S. Borrmann, R. R. Garcia, R. Portmann, L. Thomason,
L. R. Poole, D. Winker, and M. P. McCormick, 1997: Heterogeneous chlorine chemistry in the tropopause region. J. Geophys. Res., 102 (D17), 21 411-21 429.

Steinbrecht, W., M. R. Gross, T. J. McGee, R. Neuber, P. v. d. Gathen, P. Wahl, U. Klein, and J. Langer, 1998: Results of the Ny-Ålesund ozone measurements intercomparison NAOMI. Proc. 19th Int Laser Radar Conf., Annapolis, MD, NASA Langley Research Center, 347-350.

Stephens, G. L., S. C. Tsay, P. W. Stackhouse, and P. J. Flatau, 1990: The relevance of the micro-physical and radiative properties of cirrus clouds to climate and climate feedback. J. Atmos. Sci., 47, 1742-1753.

Ström, J., J. Heintzenberg, K. J. Noone, J. A. Ogren, F. Albers, and M. Quante, 1994: Small crystals in cirriform clouds: A case study of residue size distribution, cloud water content and related cloud properties. Atmos. Res., 32, 125-141.

Wandinger, U., A. Ansmann, and C. Weitkamp, 1994: Atmospheric Raman depolarization-ratio measurements. Appl. Opt., 33, 56715673 .

Wang, P.-H., M. P. McCormick, L. R. Poole, W. P. Chu, G. K. Yue, G. S. Kent, and K. M. Skeens, 1994: Tropical high cloud characteristics derived from SAGE II extinction measurements. Atmos. Res., 34, 53-83.

Young, A. T., 1980: Revised depolarization correction for atmospheric extinction. Appl. Opt., 19, 3427-3428. 